\title{
SEÑALES QUE PRECEDERÁN AL FIN DEL MUNDO DE YURI HERRERA: UNA PROPUESTA PARA UN NOVUM ONTOLÓGICO LATINOAMERICANO
}

\author{
POR \\ Giovanna Rivero \\ University of Florida
}

A mediados del siglo XX América Latina experimentó un evidente entusiasmo por el género fantástico, quizás porque el realismo mágico y las narrativas de "lo real maraviloso" habían abierto esa veta en esta parte del continente y generado una genuina necesidad de cuestionar el proyecto de la modernidad desde las alegorías. Y es que, pese a las cada vez más frecuentes catástrofes ideológicas, biológicas y políticas que el proyecto moderno ostentaba - pensemos en el holocausto, en la bomba de Hiroshima o la matanza de Tlatelolco, por citar algunas "caídas"-, persistía aún el vector de la utopía izquierdista, capaz de balancear esa naciente desilusión y transmutarla en fe en el futuro, con todo lo que ese paradigma político "futuro" implicaba. Además, desde otras orillas estéticas, lo fantástico consolidó su terreno con los universos de Jorge Luis Borges (18991986), Julio Cortázar (1914-1984) o Carlos Fuentes(1928-2012), que incorporaron en los intersticios de la realidad percepciones alternativas que, cuánticamente, reconfiguraron las lecturas históricas hasta entonces vigentes a partir de un extrañamiento sostenido, casi como si de una política ontológica se tratara.

Sin embargo, a medida que se acerca el fin de siglo y esas grietas de la modernidad van debilitando el terreno para dar paso a una concepción posmoderna de la historia, estas corrientes literarias también se debilitan en la suficiencia estética que parecía sostenerlas. En ese enclave, van emergiendo otros códigos literarios, entre los cuales se puede destacar el de una ciencia ficción "a la latinoamericana". Es así que propuestas como las de Angélica Gorodischer (1928), Copi (1939-1987), Ercole Lissardi (1951), Marcelo Cohen (1951), César Aira (1949), Edmundo Paz Soldán (1967) o Mario Levrero (1940-2004) exploran diégesis en las que ya sea la especulación como ventana epistemológica a una dimensión alternativa o ya sea un novum regional y en ocasiones rudimentario -casi una 'artesanía' - replantean el mundo como lo conocemos (desde la visión latinoamericana). En estos ejemplos, no obstante, los esquemas narrativos casi siempre se mantienen fieles al modelo clásico de la ciencia ficción, con la importante diferencia de que van asumiendo el encargo "epocal" de abordar temáticas como las 
revueltas sociales de los emergentes gobiernos populistas, la reconfiguración de la urbe por la avanzada de sus periferias, o el despertar sexual como resistencia e individuación ante la biopolítica y el biopoder cada vez más organizados. ${ }^{1}$

Es recién en los umbrales de este siglo XXI que, con la renovada necesidad de revisar los fundamentos del proyecto moderno -interrumpido por los avatares de una posmodernidad inoperante en términos ideológicos y políticos--, comienza a surgir una textualidad distinta en la frontera de la ciencia ficción y la literatura fantástica. Si bien ese borde no es nuevo, y como ejemplo fundacional podemos mencionar Frankenstein (1818) de Mary Shelley (1797-1851), y también los campos auráticos que desarrollan los cuentos de Borges y Bioy Casares, o el imaginario de Marcelo Cohen (que también juega a la comedia fantástica) y la narrativa de Angélica Gorodischer en relación a una distopía interior femenina, sí considero que la modalidad en que esas dos lógicas narrativas se interceptan ahora, en el siglo XXI, incorporando un novum atípico: el mito, nos ofrece un territorio significativamente distinto. Este novum se actualiza mediante lo que Alain Badiou denomina "resurrección” o, más específicamente, "sujeto de resurrección”. En la novela Señales que precederán al fin de mundo (2010), del escritor mexicano Yuri Herrera (1970), es posible distinguir claramente este procedimiento.

Propongo, entonces, analizar la novela de Herrera como una intersección ontológica entre lo fantástico y la ciencia ficción, que recurriendo a ambas lógicas y estéticas, y a partir de la reescritura del mito mexicano de Mictlán y de la actualización histórica de la Malinche como sujeto político subversivo y revolucionario, funda una topología alternativa en la que se reivindica la utopía latinoamericana intrínseca a la modernidad del siglo XX. Considero pertinente leer la actualización del mito a la luz de los postulados de Alain Badiou en torno al "acontecimiento" como enclave para la configuración de una nueva "verdad" histórica y/o política. Asimismo, dado el amplio espectro de connotaciones que el concepto de "modernidad" desencadena, me remitiré a la crítica que Bolívar Echeverría establece en relación a la modernidad "americana”. Esta toma de posición subcontinental será importante para comprender cómo la textualidad que se inaugura con Señales que precederán al fin del mundo nutre un tipo de imaginación latinoamericana que ya está educada en ciertos códigos narrativos, pero de los cuales se

Patricio Pron reflexiona sobre los desafíos de articular una teoría sobre la ciencia ficción en América Latina: "En ese contexto, la creación de un contrato nuevo y especifico que posibilite el uso correcto de la literatura de ciencia ficción resulta heroico y tal vez insensato debido a la falta de apoyo por parte de la industria editorial, y debería ser reemplazado por la incorporación de la ciencia ficción a lo fantástico, una solución que no debería aplicarse, sin embargo, a la ciencia ficción anglosajona, que ha tenido más éxito en establecer ese contrato debido al desarrollo de su industria cultural y a la presencia de la ciencia en la vida cotidiana". <http://www.elboomeran.com/blog-post/539/11905/patricio-pron/es-posibleuna-ciencia-ficcion-sin-ciencia-la-literatura-argentina-fantastica-y-de-ciencia-ficcion-ante-el-abismotecnologico-i/>. 
había desvinculado durante el auge de la fragmentación posmoderna que trizó el tejido ideológico y la imaginación pública.

Asimismo, en este análisis será importante revisar brevemente la función del mito en el pensamiento histórico y/o la construcción de la narrativa histórica, para entender por qué su actualización -prefiero este término al de "palimpsesto"- en la intersección ontológica ciencia ficción-relato fantástico tiene la capacidad de recuperar la utopía como vector dinamizador del interrumpido proyecto moderno. En esa línea, he optado por adherirme a los postulados de Carl Jung en torno al mito, pues el procedimiento simbólico que él establece para entender cómo el mito constituye un dispositivo por el cual los arquetipos del inconsciente colectivo se despliegan en el plano consciente a objeto de reconocer el mundo y reconocerse dinámicamente en el mundo, funciona como una bisagra entre lo que consideramos la "historia" y lo que Ernst Bloch llama "el todavía no". En otras palabras, dada su naturaleza eterna y simultáneamente maleable en su representación, el mito pone en contacto un tiempo y unos sucesos conocidos con la posibilidad abierta de otro mundo y otros sucesos, lo cual hace de esta categoría un novum epistemológico altamente pertinente a la hora de adentrarnos en el análisis de la ciencia ficción del siglo XXI.

Sin embargo, será de fundamental importancia dirigirnos con cautela al instalar este novum como recurso para retomar el proyecto moderno y la utopía que le es connatural, especialmente porque los postulados de Bolívar Echeverría cuestionan de manera frontal las implicaciones colonizadoras del mito. Echeverría diferencia entre la modernidad que se desarrolló en Europa y la modernidad que triunfó en América, concretamente en Norteamérica, dado que considera que en esa brecha reside la explicación para la profunda escisión espiritual que experimentó América Latina y que debió suturar con el tejido barroco para hacer tolerable la semilla abyecta de su fundación y nominación como continente "descubierto".

\section{El Mito DETRÁs DEL Mito}

La modernidad europea, dice Echeverría, siempre se caracterizó por la inestabilidad y la contradicción, pues el sujeto que nacía a la modernidad poseía una vocación espiritual de trascendencia que complejizaba su ser premoderno (primitivo), de tal manera que el proyecto civilizatorio se vio obligado a arrasar con esa dimensión "natural", "mítica" y "pagana" de la vida y subsumirla en su esquema capitalista. La "modernidad americana", en cambio, se enfrentó a menos contradicciones, haciendo más bien del Mito del cristianismo un aliado en su proyección económica y en su proyecto civilizatorio:

La rama "americana" de esa civilización es en cambio una rama prácticamente "pura" debido a lo tenue de ese conflicto entre lo capitalista y lo "natural"; se desenvuelve sin mayores contratiempos siguiendo una trayectoria casi rectilínea, en medio de una 
vida civilizada bastante rasa o elemental en la que la identificación "natural" de la vida por refuncionalizar se reduce, quintaesenciada, a la fe ardiente en las Sagradas Escrituras judeo-cristianas y la obediencia ciega a las directivas morales derivadas de ellas. (Echeverría, "La modernidad 'americana"" 4-5)

En ese sentido, la insistencia en la noción de una modernidad incompleta, un proyecto interrumpido por sus propias decepciones y negligencias -como así lo afirma Echeverría cuando sostiene que la pulsión por destruir para renovar ad infinitum ha hecho de la vocación moderna un proyecto esencialmente inacabado-, hace hincapié precisamente en la deficiencia más profunda (y quizás la causa) de esa incompletitud, es decir, la ausencia de un ánima de la modernidad, para decirlo con Jung. Y es que la modernización se abocó febrilmente a organizar sistemas de vida en torno a la técnica, pero intentó aniquilar el ánima original (sus ceremonias en honor a dioses pequeños o descomunales, su creencia en un camino capaz de franquear la muerte en espontánea continuidad) que debió mutar en otras modalidades, conformándose y adoptando por isomorfismo la reproducción del mito religioso de la cristiandad-y luego específicamente del catolicismo- como un elemento de control de los pueblos.

Ahora bien, un mito que sea capaz de activar la utopía -hasta ahora sobreexplotada por la pulsión renovadora de la modernización que aspiraba siempre a algo "nuevo" y "mejor"- debe entonces nutrirse de arquetipos distintos, por fuera de la teocracia judeocristiana. De allí que el procedimiento de resurrección del sujeto político mexicano que la novela de Herrera ejecuta se sostenga en el mito de Mictlán y en la figura mítica de la Malinche como umbrales de resistencia ante los relatos bíblicos mesiánicos que amoldaron la historia contemporánea de México a una ontología y cosmovisión occidentales. Por supuesto, el espacio y lenguaje ideales para esa subversión epistemológica parece ser -y así lo comprueba la narrativa de Yuri Herrera- la intersección entre la ciencia ficción y el relato fantástico. En esa intersección el mito recién puede ser concebido -no ya desde el estructuralismo barthesiano-, sino desde la dimensión subjetiva que propone Carl Jung; es decir, el mito deja de ser una unidad estrictamente a-histórica para convertirse en pura potencialidad. G. Betori lo explica de la siguiente manera en el Nuevo Diccionario de Teología Bíblica:

Es evidente que el mito no tiene ninguna pretensión de verdad histórica, en el sentido corriente de la palabra, al no ser su contenido un acontecimiento que pueda situarse en un tiempo o en un espacio específico. El tiempo y el espacio del mito son los "primordiales", precisamente para decirnos que lo que él narra es algo que nunca ha sucedido en ningún tiempo y en ningún lugar, sino que simplemente "es". Por tanto, puede decirse también que la verdad del mito pertenece a la historia, pero no en cuanto referible a la singularidad del suceso, sino a aquella dimensión última de la historicidad que está constituida por la existencia. Como tal, la verdad del mito puede proponerse siempre y a cualquier hombre. (1244)

$111 \frac{\text { Revista Iberoamericana, Vol. LXXXIII, Núms. 259-260, Abril-Septiembre 2017, } 501-516}{\text { ISSN 0034-9631 (Impreso) }}$ 
Extrapolando esa definición teológica del mito a la ciencia ficción latinoamericana, podríamos decir, entonces, que el mito contiene los requisitos del novum, como lo ha caracterizado Darko Suvin, precisamente porque desde su novedad específica vincula la totalidad, todo lo que es posible, con la existencia como laboratorio de reconfiguración de sí mismo y, en concomitancia, del mundo. Y es que, como Tom Moylan, señaló con respecto a la categoría epistemológica de novum, este artefacto de conocimiento de una realidad distinta necesita tanto de la cognición como de la imaginación y justamente en esa bivalencia se asienta su poética. Propongo, en esa línea, que el mito se presenta siempre como novedad cuando, desde la dimensión del saber popular, es trasladado a un universo textual, ya que en ese plano el mito resucita de su sueño atemporal y adquiere una pertinencia histórica revolucionaria de alta pregnancia social que, inevitablemente, va a generar el extrañamiento, requisito sine qua non "lo real" no puede ser cuestionado, subvertido o violentado. Sintetizando, el mito como antípoda y antídoto de lo real cumple la misma función de ruptura del novum tecnológico.

En otras palabras, el mito funciona como un novum porque en su recursividad administra simultáneamente la creatividad para amoldar su esquema a los eventos del azar y la subjetividad para otorgarle sentido al tiempo como un fluir exento de historicidad. Asimismo, en esta longitud de onda es posible establecer la correlación o equivalencia mito/utopía porque ambos parten de una des-historización del tiempo, pero en el transcurso de su "hacer narrativo" redimen ese tiempo vacío para convertirlo en promesa. En Señales que precederán al fin del mundo se da ese procedimiento de resignificación del tiempo eterno o cristiano a partir de una contabilidad mítica e indígena del devenir. Esa nueva crónica narrada casi imperceptiblemente en pretérito del viaje de la protagonista, Makina, hacia el Gran Chilango se ordena por fracasos o caídas, que si bien puede ser entendida como un paralelismo de la pasión de Cristo en su trayecto hacia el calvario, en todo caso consigue estetizar el transcurso imparable de los segundos y minutos desde la desaceleración del tiempo urbano y posmoderno. Daniel Link ha subrayado claramente tal recurso: “Así, la ciencia ficción (históricamente posterior a la utopía) no sería sino la despolitización (la estetización, si se prefiere) de la utopía. Esa despolitización y esa estetización son las que fundamentan el pasaje del presente discursivo de la utopía (hegemónico en Moro y Campanella, inestable en Bacon) al pasado discursivo de la ciencia ficción" (8). Es aquí, en ese pasaje temporal, que se ejecuta la intersección entre la ciencia ficción y lo fantástico, y podríamos concluir que el mito es ese novum híbrido porque es la intersección, la máquina del tiempo por excelencia.

El Mesías como Ángel de la utopía: LA SACERDotisa COMO MESías HÍBRido

Por otra parte, si bien Daniel Link tiene razón cuando menciona las diferencias originales que funcionaban para poner a cada género en su casillero, aseverando que 
la ciencia ficción propone campos semánticos en el territorio de la vida: máquinas, cyborgs, robots, androides, etc., mientras que la literatura fantástica interroga el campo simbólico de la muerte con entidades como Drácula o los zombies, considero que esa caracterización ha perdido cierta eficiencia en la medida que esta nueva mitología pos-humana imita la articulación semiótica de la mitología anterior. Así por ejemplo, en Señales que precederán al fin del mundo la Malinche pone en contacto, ya no dos mundos -el Nuevo y el Viejo-, sino más bien precisamente la vida y la muerte, como las dos fuerzas que tensionan la subjetividad del mexicano del siglo XXI, siempre pendiendo de la benevolencia sobrenatural de la Virgen de Guadalupe, pero atento a la visita arrasadora de la muerte que técnicamente se ha especializado en desmembramientos y decapitaciones.

De todos modos, hallo de profunda pertinencia la pregunta hondamente latinoamericana que Daniel Link se hace al reflexionar sobre los alcances del género de la ciencia ficción en esta parte del continente: "Lo que habría que discutir, entonces, es si en la ciencia ficción, o en cualquier otro género literario, pueden encontrarse las temáticas que habrían de orientar hoy el anhelo utópico, si lo que la ciencia ficción propone en pasado, por ley del género, puede pensarse en presente como utopía" (15).

Una posible respuesta a ese planteamiento proviene, precisamente, de los postulados de Bolívar Echeverría que encuentra en la recuperación de una forma de vida "natural" (primaria, primitiva, indígena) la vía para que el anhelo utópico corresponda a una sensibilidad y a una cosmogonía latinoamericanas, y de esta manera no termine traicionando su propia condición de anhelo, deseando un deseo ajeno. Así pues, “[...] como primera contraposición histórica al ethos realista, se encuentra además el ethos 'barroco', de acuerdo al cual, y mediante una escenificación que invierte el sentido de la realidad, la destrucción capitalista de la 'forma natural' de la vida y sus valores de uso es experimentada prácticamente como inefectiva o impotente" (Echeverría, "La modernidad 'americana"' 8). En efecto, en la novela de Herrera, que comienza con el éxodo de Makina, una joven telefonista que sabe tres idiomas, y que debe partir al Norte en busca de su hermano, se desmonta sistemáticamente toda la parafernalia del progreso moderno occidental, denunciando una estafa que se ha filtrado por la técnica y la tecnología. Por ejemplo, los celulares que quienes regresan ostentan como una adquisición magnífica no funcionan bien, y son rebajados inmediatamente a fósiles extraños, incapaces de establecer aquello que la comunidad necesita como única vía de salvación: comunicación, discurso, palabra. En oposición a esa insuficiencia del progreso extranjero, Makina ofrece su "mediumnidad" lingüística y emocional, toda vez que su misión no consiste sólo en traducir llamadas telefónicas, sino en reconciliar novios o traducir emociones en palabras.

Otra respuesta a esa inquietud de cómo concebir una ciencia ficción latinoamericana que describa y porte una utopía también latinoamericana y ya no sólo una utopía-

$111 \frac{\text { Revista Iberoamericana, Vol. LXXXIII, Núms. 259-260, Abril-Septiembre 2017, } 501-516}{\text { ISSN 0034-9631 (Impreso) }}$ 
proyección del deseo europeo y occidental reside, justamente, en la construcción de una figura mesiánica que sintonice los arquetipos más profundos de América Latina. En "Modernidad y capitalismo", Bolívar Echeverría hace notar una de las razones por las que la utopía de la modernidad del siglo XX fracasó y cedió paso a ese punto muerto llamado "posmodernidad". Lo dice así:

Originado en la muerte de "la otra mitad de Dios" - la de su divinidad como dimensión cohesionadora de la comunidad-, es decir, en el fracaso de la metamorfosis arcaica de lo político religioso, el individualismo conduce a que la necesidad social de colmar esa ausencia divina y a la vez reparar esa desviación teocrática de lo político sea satisfecha mediante una re-sintetización puramente funcional de la substancia social, [...] en la figura artificial de la nación. (484-5)

Por eso, cuando la Nación se hace Mito para ocupar el lugar negligente de Dios, el sujeto prehispánico que late y subyace, a punto de resucitar, en una figura como la de Makina, se ve obligado a abominar de ella. El éxodo masivo hacia el Gran Chilango y luego la decepción ante la falacia del propio Gran Chilango son expresiones de ese aborrecimiento antinacional. De ahí que Señales que precederán al fin del mundo sea, a un tiempo, el territorio perfecto para la ciencia ficción latinoamericana y el páramo fantástico de la misma genealogía de Comala, es decir la utopía como el lugar que no es posible.

¿Cómo, entonces, entender que Makina toma el lugar del mesías sin volver a colonizar, bajo el mito judeo-cristiano a sus hermanos y hermanas? Intentaré responder a esta inquietud con el desarrollo de una breve genealogía de la utopía y el mesianismo. Tenemos, entonces, que la utopía de Walter Benjamin se prefigura en la psiquis, en los arquetipos más secretos del hombre, donde sin duda reside el mito mesiánico que Benjamin va a reformular en búsqueda de una esperanza funcional, en correspondencia con Bloch:

These images are wishful fantasies, and in them the collective seeks both to preserve and to transfigure the inchoateness of the social product and the deficiences in the social system of production [...] Intimations of this, deposited in the unconscious of the collective, mingle with the new to produce the utopia that has left its traces in thousands of configurations of life [...]. (148)

Benjamin postuló una idea aun más radical respecto a la cronología de la utopía. Así, mientras para Bloch la utopía se realiza al final de los tiempos o no se realiza necesariamente, Benjamin humaniza el advenimiento del momento utópico. Sugiere que en la flecha de la historia ocurren distintos momentos en que el mesías se expresa y/o viene al encuentro del hombre. Para ello es necesario que el hombre, en su proceder 
profano, busque la felicidad de un modo militante, y entonces la utopía se realiza como un encuentro inesperado entre esas dos naturalezas y entre esos dos tiempos, uno individual, otro absoluto, casi por azar o -como lo formula Badiou- como un "deseclipse": "Only the Messiah himself consummates all history, in the sense that he alone redeems, completes, creates its relation to the Messianic. For this reason nothing historical can relate itself on its own account to anything Messianic. [...] the order of the profane should be erected on the idea of happiness" (Benjamin, Selected Writings 312).

El aporte de Fredric Jameson tiene, a diferencia de los dos autores anteriores, un tenor más oscuro, pues Jameson propone el binomio ideología-miedo como la base para poner en circulación una "utopía negativa". En el ensayo "La política de la utopía" (2006), Jameson establece una posible génesis para el deseo utópico: “[...] la utopía surge en un momento de suspensión de lo político". ${ }^{2}$ Jameson considera que la política es siempre histórica, su velocidad y riesgos de deterioro y transformación son vectores que corren paralelos a la historia. Sin embargo, cuando esa velocidad se coagula y la posibilidad de cambio - que es intrínseca a un programa político-se anula, entonces el pensamiento utópico se torna imprescindible. El surgimiento de ese momento utópico entraña una negatividad dialéctica, pues sólo en esa dosis negativa -asegura Jamesones posible movilizar lo que se había suspendido:

[...] la utopía es de algún modo negativa, y cuando más auténtica resulta, es cuando no podemos imaginarla. Su función no estriba en ayudarnos a imaginar un futuro mejor, sino más bien en demostrar nuestra total incapacidad para imaginar un futuro tal -nuestro encarcelamiento en un presente no utópico sin historicidad ni futuridad-a fin de revelar el cierre ideológico del sistema en el que de algún modo nos encontramos atrapados y confinados. (La política...)

Entrada ya la primera década del siglo XXI Badiou publica su obra Lógica de los mundos (2006), en la que revisa y profundiza en su "Teoría del sujeto". En ella articula una taxonomía formal del sujeto, pues piensa el cuerpo físico como portador de una subjetividad, pero también como una potencia política elemental capaz de transformar el presente. El tiempo presente es un criterio axial en las reflexiones sobre el cambio político. La inducción del cambio, de la transformación del "desastre" en nueva "verdad" se da por vía de una dialéctica que escinde al sujeto, quien ya no está cómodo en sus actuales coordenadas tempo-espaciales: "la dialéctica del espiado [esplace] (digamos, más sobriamente, de los mundos) y del fuerlugar [horlieu] (digamos, de los sujetos que inducen, como forma de un cuerpo, las verdades)" (Lógica 1).

2 Esta "suspension de lo político" podría ser decodificada, en clave de Alain Badiou, como el momento del "deseclipse". No establezco abiertamente esa comparación porque me parece apresurado y contradictorio asumir que la ausencia de "lo político" sea algo deseable en la concepción de Badiou. 
Badiou distingue tres sujetos que desde la antigüedad, bajo el dominio de los imperios, hasta el siglo XX, con la democracia que coronó a la burguesía, han resignado la potencialidad de su agencia a cambio de no morir, de dejar de "ser", o quizás simplemente de dejar de "estar". Badiou sentencia: "El materialismo democrático no conoce más que individuos y comunidades, es decir, cuerpos pasivos, pero de ningún modo sujetos" (Lógica 5). Estos cuerpos pasivos se clasifican en "el sujeto fiel", que se pliega a los modos de producción del presente -equivalente quizás al utopofóbico de Darko Suvin-; "el sujeto reactivo", que no sólo es utopofóbico por resistirse al cambio, sino también por ser un sujeto militantemente pesimista; y "el sujeto oscuro" que promueve la ocultación de las verdades humanas en pro de las verdades sistémicas -equivalente al sujeto religioso-.

El principal aporte de Badiou al linaje de los pensadores de la utopía consiste, en mi opinión, en la cuarta categoría formal del sujeto: "el sujeto de resurrección". Afirma Badiou que un verdadero acontecimiento se expresa con los fundamentos del comunismo, pero del verdadero comunismo, no del que se ha corrompido por los pactos de la modernidad al punto de generar sociedades en las que prevalece "un comunismo sin comunidad". Ahora bien, para que ese acontecimiento revelador se desencadene es preciso que se despliegue el amor. ${ }^{3} \mathrm{Y}$ es esta cuarta fuerza y lenguaje, el amor, lo que permite que el presente se transforme o despliegue en su simultaneidad: "De todo presente verdadero se tiene derecho a esperar que un presente nuevo, que active la desocultación, haga aparecer el esplendor perdido en la superficie salvadora de un cuerpo" (Lógica 17.)

Por todo ello, considero que Makina es la mesías de una nueva "verdad" histórica posnacional y posmexicana, concretamente, pero también pos-imperial. El suyo es un doble viaje: el viaje político del mártir y el viaje religioso de la sacerdotisa. Sabe que al cruzar la frontera ilegalmente está ofrendando su vida y uniéndose a la comunidad para morir con ella, pero sólo a través de esta ofrenda es que conseguirá devolverle a los suyos enajenados la noción de una dignidad pospatriótica también y que consiste en la pertenencia a un hogar primario anterior a toda la historia occidental.

\section{MAKINA COMO SUJETO DE RESURRECCIÓN}

México nace de una catástrofe. La conquista española que implicó el genocidio de los indios y la abolición de esa subjetividad originaria está presente en la mayoría de los novelistas e historiadores que han caído en la tentación de narrar los distintos

3 Badiou sostiene que el amor, el arte, la política y la ciencia son procedimientos genéricos que habilitan la expresión del sujeto. Sin ellos, el sujeto sería pura abstracción. Así pues, sólo puede existir "el sujeto científico", "el sujeto artista", "el sujeto político" y "el sujeto amoroso". Nótese también que otras traducciones prefieren usar la preposición "para": "sujeto para el amor", pero intuyo una mediación peligrosa en esa sintaxis. 
tiempos de México. Alfonso Reyes (1889-1959), Juan Rulfo (1917-1986), Octavio Paz (1914-1998) y Carlos Fuentes (1928-2012), por citar algunos, han dado cuenta de esa catástrofe que, a manera del "pecado original" bíblico proyecta su impronta a lo largo de la modernidad. Octavio Paz asegura, por ejemplo, que "La extraña permanencia de Cortés y de la Malinche en la imaginación y en la sensibilidad de los mexicanos actuales revela que son algo más que figuras históricas: son símbolos de un conflicto secreto, que aún no hemos resuelto" (El laberinto de la soledad 95).

Pero aun cuando se despliegue un esfuerzo por resolver el mito, por romper sus ataduras para intentar imaginar un México distinto, el modo de enunciación continúa funcionando como un corsé. Por ejemplo, cuando Alfonso Reyes en "Visión de Anáhuac" describe el valle como un paraíso exuberante condenado a perecer por su propio exceso, o cuando Carlos Fuentes detalla las razones de la derrota y escribe: "Nunca pudo un indio encontrar la manera de vencer a un jinete castellano armado y este es el verdadero secreto de la Conquista, no sueño o profecía alguna" (Los cinco soles de México 50), confirma lo que Suvin llama el "locus" en contraposición al "horizonte". México se instituye así como su principal obstáculo para su propia universalización. Su catástrofe se singulariza de tal manera que no puede ser insertada en la historia universal. El esfuerzo de Reyes por hacer de Anáhuac un correlato del Olimpo no llega a ser suficiente, por lo menos no para su época.

En Señales que precederán al fin del mundo, Yuri Herrera vuelve a la figura mítica de la Malinche para, a partir de su vida como viaje hacia la utopía de un territorio posmexicano y posterrenal, elaborar un proceso de redención que le devuelva a México la confianza en su propia historia, la historia obliterada y oculta o, en todo caso, sintetizada por el barroco. La novela abre su éthos distópico justamente desde el título, explícitamente apocalíptico, es cierto, pero que es también susceptible de una decodificación bajo el "principio esperanza". Esas señales constituyen justamente la espera de un proceso que está por terminar y que puede ser leído como el "mundo occidental", el mundo de los otros, el mundo impuesto y yuxtapuesto desde la Conquista por sobre la sensibilidad original y prístina de los habitantes de Anáhuac.

Sin embargo, como ya he mencionado, en este breve análisis propositivo me interesa enfocarme en la construcción de Makina, el personaje central, pues es su figura la que porta el novum necesario para que los sujetos resurrectos se reapropien de la historia mexicana y elaboren una nueva textualidad y un nuevo discurso sobre su propio devenir. Sobre la cronología de esta obra, articulada conforme a los distintos estadios del mito de Mictlán, se ha escrito bastante. Esas nueve "postas" que el caminante debe desafiar en su ruta con rumbo Norte, hacia Mictlán, el lugar o inframundo donde los muertos llegan para ser redimidos, han sido interpretadas, con gran frecuencia, como la directa alegoría del éxodo desaforado de los mexicanos pobres hacia Estados Unidos. Por ejemplo, para Edith Mora Ordoñez la emigración hacia Estados Unidos como la utopía

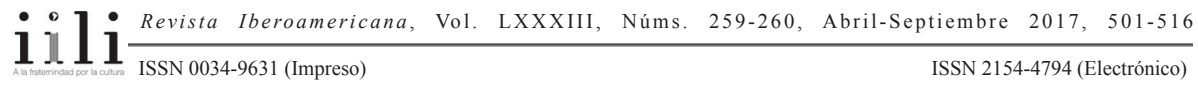


económica no tiene otra opción que terminar en el resquebrajamiento de esa utopía, pues es esa desilusión irónicamente lo que llena de sentido el nomadismo existencial:

El destino es, por lo tanto, una espiral. Dado que "el hombre construye según un arquetipo", ${ }^{61}$ el espacio creado por el inmigrante que se instala junto a sus iguales en los límites de la frontera, tiene características similares al inframundo anterior. Esto es si lo único verdaderamente real son los arquetipos, ${ }^{62}$ y esto equivale a respetar las leyes tradicionales, entendemos que el individuo tiende por acción lógica a repetir su esquemas de modo de vida.

Dicha concepción cíclica de la repetición de los acontecimientos parte de la idea de Nietzsche sobre el eterno retorno (La gaya ciencia 1882), que entendemos aquí a partir de lo desarrollado por M. Eliade, desde una visión optimista de regeneración. Sin embargo, el caso que presentamos incluye la fatalidad de los mitos actuales al no tener ese carácter positivo de progreso. ${ }^{63}$ Opera en sentido contrario en la frontera norteamericana ocupada por los mexicanos, donde se cumple el determinismo de la tierra herida, infecunda, muerta. (291-292)

Es cierto que el viaje de Makina no prospera, pero se trata del viaje terrenal, y lo que me interesa proponer es justamente un sesgo a esa lectura un tanto sociológica. Considero, pues, que el triunfo existencial de Makina ocurre desde el lado oscuro de la utopía, cuya potencialidad negativa puede llegar a ser incluso más poderosa por su capacidad de perversión histórica, como lo ha señalado Fredric Jameson.

De todos modos, la misión ontológica del "novum Makina" no es exclusivamente la denuncia alegórica del fracaso irresoluble que significa la inmigración ilegal mexicana y cómo ese fenómeno es ya una semilla para componer una alternativa insospechada. ${ }^{4}$ En contrapartida, la alusión enunciativa bastante clara, por cierto, a Marina o Malinche plantea una sugerencia fáctica que el lector latinoamericano no puede pasar por alto.

En La modernidad de lo barroco (1998), Bolívar Echeverría enfatiza el rol fundamental que tuvo la Malintzin, Malin o Malinali desde el momento en que fue bautizada como "Marina". Su papel de intérprete entre "[...] dos interlocutores colosales, dos mundos o dos historias" (21), Cortés y Moctezuma, la colocó en el dilema histórico de si considerarla una traidora (¿acaso no fue la primera traductora?) o una embajadora. En todo caso, como lo postulo en este ensayo, la encarnación que Yuri Herrera hace de ese personaje mítico en la caracterización de Makina la perfila como el gran novum de un momento histórico, cinco centurias después, que tiene escalofriantes puntos de contactos

${ }^{4}$ La creciente difusión al interior del campo cultural estadounidense de una producción cinematográfica mexicana que narra los avatares de los migrantes y la problemática de la frontera constituye, de algún modo, una suerte de pacto compensatorio entre la cultura "invasora" y la cultura "expulsora". Esta textualidad audiovisual va fundando un imaginario mexicano de frontera justamente en el seno del territorio ajeno, generando lo que el novum debe provocar: inestabilidad cultural.

$111 \frac{\text { Revista Iberoamericana, Vol. LXXXIII, Núms. 259-260, Abril-Septiembre 2017, } 501-516}{\text { ISSN 2154-4794 (Electrónico) }}$ 
con aquella primera Conquista. Ahora como entonces, un imperio desea poseer otro territorio, sólo que desde el revés o el negativo, pues esta suerte de imperio derrotado que es México avanza, imparable, en pos de la colonización de la utopía del Norte.

Empero, a objeto de no circunscribirme a esa interpretación alegórica de la migración -como ya lo he apuntado- vuelvo a lo que Echeverría hace notar con respecto a la innegable trascendencia que la función traductora de la Malinche implicó durante el gran encuentro. Como mediadora entre dos mundos, Marina se enfrentó a la amenaza del malentendido, un malentendido que ha transmutado en el "éthos barroco" con el fin de hacer tolerable y disfrutable esa coexistencia. Echeverría reflexiona:

\begin{abstract}
Ante esta futilidad de su esfuerzo de mediación, ante esta incapacidad de alcanzar el entendimiento, la práctica de la interpretación tiende a generar algo que podría llamarse "la utopía del intérprete". Utopía que plantea la posibilidad de crear una lengua tercera, una lengua-puente, que, sin ser ninguna de las dos en juego, siendo en realidad mentirosa para ambas, sea capaz de dar cuenta y de conectar entre sí a las dos simbolizaciones elementales de sus respectivos códigos; una lengua tejida de coincidencias improvisadas a partir de la condena al malentendido. (La modernidad de lo barroco 22)
\end{abstract}

En efecto, Makina, ya sea por aliteración o metaplasmo u otro tropo, es Marina. Como encargada de la pequeña y única centralita telefónica del pueblo, Makina es, pues, la "máquina" que interpreta, el novum por excelencia en un espacio donde las lenguas constituyen metonimias de distopías crueles por lo incomunicadas. Pero Makina sabe inglés, español y otra lengua indígena y por eso puede administrar la centralita, haciendo de traductora entre los que llaman del "Gabacho" y los provincianos que esperan esos anuncios. Ella está consciente de ese encargo histórico, de su misión de unir fronteras, por eso afirma: "Una no escoge cuáles mensajes lleva y cuáles deja pudrir. Una es la puerta, no la que cruza la puerta” (19).

A propósito de esa condición de máquina cultural que Makina asume, me parece adecuado mencionar lo que Daniel Link ha dicho, justamente, en relación a los sustratos de género que subyacen en la ciencia ficción. Link asegura que la emergencia de la máquina en sus versiones protohumanas y pos-humanas -el cyborg, el androide, el alien- ha desestabilizado la identidad del hombre como ser sexuado, de tal modo que es necesario pensarlo desde su dialéctica con la máquina. Así pues, Makina es la máquina con la que la cultura copula.

Asimismo, el discurso, la palabra, el hacer narrativo son de cardinal importancia en la composición diegética de la novela de Herrera. "Jarchar", por ejemplo, es un término que se instaura como símbolo del constante desplazamiento, de la naturaleza dinámica de la utopía. Makina dice y se dice cosas constantemente, en una pulsión por nombrar el universo y someterlo a sus leyes de traductora; de tal modo que cuando se reconoce "muerta" es cuando comienza realmente a resucitar, pues es así, desde la iniciación en 
la muerte, como en su verdadera patria funciona la existencia: "Estoy muerta, se dijo Makina, y apenas lo había dicho su cuerpo entero comenzó a resistir la sentencia y batió los pies desesperadamente hacia atrás, cada paso a un pie del deslave, hasta que el precipicio se definió en un círculo de perfección y Makina quedó a salvo. Pinche ciudad ladina, se dijo, Siempre a punto de reinstalarse en el sótano" (11).

No es, insisto, la espacialidad el lugar utópico que Makina va a conquistar con su éxodo, con su inexorable "jarchar" hacia el Gran Chilango, sino un lugar suspendido, sostenido por la interrelación humana. De hecho, Makina atraviesa y deconstruye con su desconfianza la materialidad de un mundo que es, por su naturaleza incansablemente capitalista, una falacia. Así lo podemos evidenciar en este enunciado: "Miró los espejos: al frente estaba su espalda: miró detrás y sólo halló el interminable frente curvándose, como invitándola a perseguir sus umbrales. Si los cruzaba todos eventualmente llegaría, trascurvita, al mismo lugar; pero de ese lugar desconfiaba" (24).

En cambio, cuando Makina entra en comunión con sus iguales, con sus hermanos desperdigados en el sinsentido deléxodo, es el momento en que se da el "acontecimiento" y la "verdad" mesiánica y política que propone Alain Badiou. Makina, en ese sentido, se erige como la Mesías esperada porque hay quien la espere y ella puede colmar esa espera:

Son paisanos y son gabachos y cada cosa con una intensidad rabiosa [...]. Tienen gestos y gustos que revelan una memoria antiquísima y asombros de gente nueva. Y de repente hablan. Hablan una lengua intermedia con la que Makina simpatiza de inmediato porque es como ella: maleable, deleble, permeable, un gozne entre dos semejantes distantes y luego entre otros dos, nunca exactamente los mismos, un algo que sirve para poner en relación. [...] entre lo que desaparece y lo que no ha nacido. (73)

De este modo Makina confirma y reafirma su función de novum ontológico. La intermediación entre la vida y la muerte, entre el pasado prehispánico y ese presente extraño plagado de occidentalidad, desafían a Makina en su función redentora. Con ese cometido ella debe desentrañar los intersticios de las lenguas y resucitar lo que ha estado muerto durante siglos, los valores antieconómicos que en su comunidad originaria constituían el éthos. Makina, mediante ese lengua resucitada, resucita a su vez y da vida nueva al cosmos: "[...] si uno dice Dame fuego cuando ellos dicen Dame una luz, ¿qué no se aprende sobre el fuego, la luz y sobre el acto de dar? No es que sea otra manera de hablar de las cosas: son cosas nuevas. Es el mundo sucediendo nuevamente [...]" (74).

Finalmente, en la escena del desenlace, en el último estadio del mito de Mictlán, Herrera narra el encontronazo entre el poder occidental y el migrante extraviado a partir de la caracterización de un policía fronterizo que interpela a un agricultor "ilegal" o "indocumentado" preguntándole por lo que tiene escondido: "Ja, dijo el policía tras ojearlo, Poemas. Vaya con la mano de obra calificada, no traen dinero, no traen documentos, pero traen poemas. ¿Eres muy romántico? ¿Eres poeta? ¿Eres escritor? Pues ahora vamos 
a ver" (108). La alusión a los evangelios cristianos no es directa, pero ortogonalmente podríamos asumir que esos poemas venidos desde el pasado, desde el México abyecto, son peligrosos porque pueden contaminar la lógica racional de la historia occidental.

Es en ese momento, cuando el indocumentado es expropiado hasta de su capacidad poética por la cual puede domesticar el horror del mundo, que Makina interviene y se erige mesiánicamente como una vía de salvación a través del discurso. Toma, pues, el lápiz y el cuaderno del indocumentado y escribe, es decir, funda, hiende huella, reorganiza la historia universal:

Nosotros somos los culpables de esta destrucción, los que no hablamos su lengua ni sabemos estar en silencio. Los que no llegamos en barco, los que ensuciamos de polvo sus portales los que rompemos sus alambradas. Los que venimos a quitarles el trabajo, los que aspiramos a limpiar su mierda, los que anhelamos trabajar a deshoras. Los que llenamos de olor a comida sus calles tan limpias, los que les trajimos la violencia que no conocían, los que transportamos sus remedios [...] Los que quién sabe qué aguardamos. Nosotros los oscuros, los chaparros, los grasientos, los mustios, los obesos, los anémicos. Nosotros, los bárbaros. (109-110)

Con la misma performatividad del Antiguo Testamento que diciendo "hágase la luz" da vida al cosmos, Makina nombra las identidades de estos habitantes nuevos de la utopía negativa, que no por negativa es menos hermosa, deseada y redentora. Así es, ellos son "los bárbaros", ardientes y santificados por el anhelo de conquistar esa "tierra de las oportunidades". Su redención no puede reducirse o simplificarse en una suerte de venganza pero sí de subversión, toda vez que los "quehaceres" de estos bárbaros no alcanzan una escala industrial, son otra vez obreros, en contacto pueril con el trabajo, haciendo del trabajo su revolución política.

Señales que precederán el fin del mundo cierra con la muerte física y simbólica de Makina, pero también con su resurrección en un plano espiritual, volviendo a sí al esquema ideológico que le ha insuflado vida: el mito. De allí que otra posibilidad de interpretación para esta propuesta de Yuri Herrera sea el que Makina ocupa noúnicamente el lugar de Marina o Malinche, sino el de una traducción sincrética entre el Cristianismo y la femineidad "chingada" del México prehispánico: Makina es también la Virgen de Guadalupe, invencible, rizomática, utópica.

Amanera de conclusión me parece oportuno añadir que la extensión de esta novela no es ambiciosa -119 páginas-, factor que consolida su capacidad narrativa para condensar la potencia afectiva e ideológica del mito latinoamericano en un relato que comparte el aura de lo fantástico con la proyección utópica y la radicalización política de la ciencia ficción. A modo de enfatizar la irrupción de esta breve gran obra narrativa, permítaseme adoptar la valoración que Julio Ortega esgrime en el prólogo de Mutantes (2007): “[s] ería, claro, un tardío romanticismo anticapitalista creer que el campo cultural (hoy día 
ocupado por la práctica globalizadora, por el modo de producción homogénea) puede ser subvertido por un libro o por un escritor. Pero un libro puede, eso sí, confirmar un espacio no-sistemático, libre de la polaridad dominante, y abrir un margen, un lugar deshabitado por la angustia de influir, casi un horizonte de relevos" (27). Eso es justamente lo que consigue la novela de Yuri Herrera, abrir, en/desde la intersección con lo fantástico, un irreversible margen para la ciencia ficción latinoamericana.

\section{BiBLIOGRAFÍA}

Badiou, Alain. Lógicas de los mundos. Buenos Aires: Editorial Manantial, 2008.

La ética. Ensayo sobre la conciencia del mal. <http://www.elortiba.org/badiou. html>. 29 enero 2014.

Introducción a El ser y el acontecimiento. Acontecimiento 16 (1998). <http:// www.grupoacontecimiento.com.ar/>.4 feb. 2014.

"El despertar de la historia". El País. 8 mayo 2012. <http://blogs.elpais.com/ tormenta-de-ideas/2012/05/el-despertar-de-la-historia.html>. 10 feb. 2014.

Benjamin, Walter. Selected Writings. Vol. 3. Edmund Jephcott, trad. Cambridge: Beknap Press, 2002.

Betori, G. "Mito". Nuevo diccionario de teología bíblica. Pietro Rossano, Gianfranco Ravasi y A. Girlanda, eds. Madrid: Ediciones Paulinas, 1990. 1234-1256.

Bloch, Ernst. The Utopian Function of Art and Literature: Selected Essays. Massachusetts: MIT P, 1988.

Echeverría, Bolívar. "La modernidad 'americana"”. <http://ww.bolivare.unam.mx/ ensayos/La\%20modernidad\%20americana.pdf>. 14 oct. 2008.

La modernidad de lo barroco. México, DF: Ediciones Era, 1998.

"Modernidad y capitalismo: quince tesis". Review (Fernand Braudel Center) XIV/4 (1991): 471-516.

Herrera, Yuri. Señales que precederán al fin del mundo. España: Editorial Periférica, 2010.

Fuentes, Carlos. Los cinco soles de México. Memoria de un milenio. México, DF: Seix Barral, 2000.

Jameson, Fredric. Archaeologies of the Future. Londres: Verso, 2005.

"La política de la utopía". AdVersus III/6-7 (2006). <http://www.adversus.org/ indice/nro6-7/articulos/articulo_jameson.htm>. 31 enero 2014.

Jung, Carl Gustav. Synchronicity, an Acasual Connecting Principle. Princeton: Princeton UP, 1973.

Link, Daniel. Escalera al cielo, utopía y ciencia ficción. Buenos Aires: La Marca Editora, 1994.

$111 \frac{\text { Revista Iberoamericana, Vol. LXXXIII, Núms. 259-260, Abril-Septiembre 2017, } 501-516}{\text { IISSN 0034-9631 (Impreso) }}$ 
Mora Ordoñez, Edith. "Del sueño americano a la utopía desmoronada: cuatro novelas sobre la inmigración de México a Estados Unidos". Revista de Estudios Latinoamericanos LIV (2012): 269-295.

Ortega, Julio y Juan Francisco Ferré. Mutantes, narrativa española de última generación. España: Editorial Berenice, 2007.

Paz, Octavio. El laberinto de la soledad. México: Fondo de Cultura Económica, 1996.

Pron, Patricio. "¿Es posible una ciencia ficción sin ciencia? La literatura argentina fantástica y de ciencia ficción ante el abismo tecnológico (y II)". <http://www. elboomeran.com/blog/539/patricio-pron/etiqueta/disidencias/20/>

Reyes, Alfonso. "Visión de Anáhuac". Obras completas de Alfonso Reyes. Vol. II. México: Fondo de Cultura Económica, 1997. 